\title{
Numerical Simulation of Luminescent Downshifting in Top Cell of Monolithic Tandem Solar Cells
}

\author{
Mahfoud Abderrezek, ${ }^{1,2}$ Mohamed Fathi, ${ }^{1}$ Farid Djahli, ${ }^{2}$ and Mohammed Ayad ${ }^{1}$ \\ ${ }^{1}$ UDES, Solar Equipment Development Unit/EPST CDER, RN11 Bou-Ismail BP. 386, 42415 Tipaza, Algeria \\ ${ }^{2}$ L.I.S Laboratory, Department of Electronic, Faculty of Technology, Ferhat Abbas University, 19000 Setif, Algeria \\ Correspondence should be addressed to Mahfoud Abderrezek; mahfoud_cbi@yahoo.fr
}

Received 20 May 2013; Revised 8 July 2013; Accepted 10 July 2013

Academic Editor: Gaetano Di Marco

Copyright (c) 2013 Mahfoud Abderrezek et al. This is an open access article distributed under the Creative Commons Attribution License, which permits unrestricted use, distribution, and reproduction in any medium, provided the original work is properly cited.

\begin{abstract}
The increase in the conversion efficiency of monolithic tandem solar cells is limited by the short-circuit current density matching between the top and the bottom cells. Generally, the top cell presents the lowest current in the two subcells. In this paper, in order to increase the short-circuit current density in the top cell, we present a theoretical survey of the luminescence downshifting (LDS) approach for the design of monolithic tandem solar cells. The photovoltaic (PV) glass encapsulation material is replaced with a polymer material of polymethyl methacrylate (PMMA) type which is doped with diverse kinds of organic dyes. The performance of the $n-p-p+$ GaInP structure has been simulated as a function of the organic dyes. Gains achieved for the short-circuit current density and conversion efficiency are, respectively, $13.13 \%$ and $13.38 \%$, under AM1.5G illumination spectra.
\end{abstract}

\section{Introduction}

Multijunction solar cells can increase the efficiency of the cell by introducing another semiconductor able to reduce losses in high energy photons. There are three approaches, monolithic cells, mechanically stacked cells, and spatialconfiguration approaches [1]. The monolithic solar cells present an elegant approach in reducing the number of processing steps by using a single substrate, but it requires two main conditions: first, the thin layers of epitaxial semiconductors must have closer lattice constant parameters, and second, we must have an adequate current matching between subcells. However, in this series connection, the subcell with the lowest photocurrent, limits the current generated by the full device structure [1,2]. To fulfill the second criterion, we must adjust the top cell thickness because it presents lower short-circuit current density compared with the bottom cell of the tandem structure. Generally, we adjust short-circuit current density by adjusting the thickness of the top cell's base layer [2].

In 1990, under one-sun air mass 1.5 global radiation (AM1.5G) condition, efficiencies greater than 27\% were achieved by changing the top-cell thickness to ensure current matching $[3,4]$. However, increasing the thickness of the base layer in the top cell leads to an increase in absorption losses, the radiances in tandem solar cells are attenuated exponentially with respect to the thickness of layer.

In the present study, we propose an alternative method to increase the short-circuit current density in the top cell, based on the manipulation of the incident spectrum before its absorption by the solar cell; the idea is to substitute PV glass encapsulation materials with a thin layer of polymer material PMMA doped with optically active components. It has been shown in previous works that this approach results in performance improvement on some single junctions (CdTe, mc-Si, c-Si, GaAs, and CIGS) [5-7]. Besides, it reduces the cost and weight of the final PV module.

\section{Materials and Methods}

2.1. Luminescence Downshifting Principle. Originally, luminescent Downshifting (LDS) was first proposed in the late seventies by Hovel et al. [8]. The LDS approach is based on shifting parts of high energy photons from the ultraviolet (UV) region where the quantum efficiency (QE) of the cell is poor to the visible and infrared regions where the $\mathrm{QE}$ is 
TABLE 1: Optical properties of diver's kinds of dyes used.

\begin{tabular}{lccccc}
\hline Dyes & Absorption range $(\mathrm{nm})$ & Emission range $(\mathrm{nm})$ & Max abs. $(\mathrm{nm})$ & Max emis. $(\mathrm{nm})$ & LQE $(\%)$ \\
\hline Violet 570 & $300-410$ & $400-520$ & 378 & 413 & 94 \\
Yellow 083 & $350-500$ & $460-600$ & 476 & 490 & 99 \\
Orange 240 & $440-550$ & $520-650$ & 524 & 539 & 100 \\
\hline
\end{tabular}

higher. A thin layer of PMMA doped with organic dyes plays the role of a photon converter; it absorbs UV photons before they are absorbed by the encapsulated material and emits them in a longer wavelength. Figure 1 illustrates the concept of downshifting introduced by organic dyes on the AM1.5G solar spectrum [9]. Also, we see that the GaInP solar cell uses photon energies in the range between $300 \mathrm{~nm}$ and $660 \mathrm{~nm}$; it has a significant visible spectrum and a poor sensitivity in the violet and blue regions [10].

For better matching between the LDS layer and the response of GaInP solar cell, organic dyes need to be selected to absorb photons at a short wavelength, where the GaInP cell exhibits low quantum efficiency, then reemits them at a longer wavelength where the solar cell exhibits a significantly better response.

\subsection{Encapsulation Material and Luminescent Dyes. Poly-} methyl methacrylate (PMMA) is an excellent photovoltaic encapsulation material which was introduced recently in the manufacturing process of photovoltaic modules. It has a set of appealing mechanical and optical properties [11], in addition to its high transmittance spectrum along the region where the solar cell's response is high. PMMA is robust against heat treatments that the solar cells undergo during their manufacturing process; besides, it has a photostability extending over long periods of 20-25 years [10]. It is also recyclable and has an excellent stability against ultraviolet (UV) radiations [12].

In the present study, we will investigate the three fluorescent organic dyes (BASF Lumogen Violet 570 (V570), Yellow 083 (Y083), and Orange 240 (O240)) [13]. They are all made of napthalomide and perylene molecules, manufactured by BASF (Ludwigshafen, Germany). These organic dyes were studied in several papers of McIntosh et al. [12,14]. They have many features; namely, they are cheap, photostable to UV, and easy to process in polymeric matrices, and they exhibit near-unity luminescence quantum efficiencies (LQE) [6]. The optical properties of dopants are listed in Table 1.

2.3. GaInP Devices. In this work, we have introduced an LDS layer on the top cell of the monolithic tandem solar cell studied by Takamoto et al. [21]. Figure 2 shows a schematic diagram of the tandem solar cell studied with LDS layer. The technological parameters for the different layers (thickness and doping level), used in this paper, are the same as those used by Takamoto et al. [21]. The top cell consists of a layer $p+\mathrm{Ga}_{0.5} \operatorname{In}_{0.5} \mathrm{P}$ BSF, a base layer $p \mathrm{Ga}_{0.5} \operatorname{In}_{0.5} \mathrm{P}$, an emitter $n+$ $\mathrm{Ga}_{0.5} \mathrm{In}_{0.5} \mathrm{P}$, and the window $n+\mathrm{Al}_{0.52} \mathrm{In}_{0.48} \mathrm{P}$. The $\mathrm{ZnS} / \mathrm{MgF}_{2}$ antireflection coating (ARC) layer allows the reduction of the average reflectivity in the wavelength region between 400 and

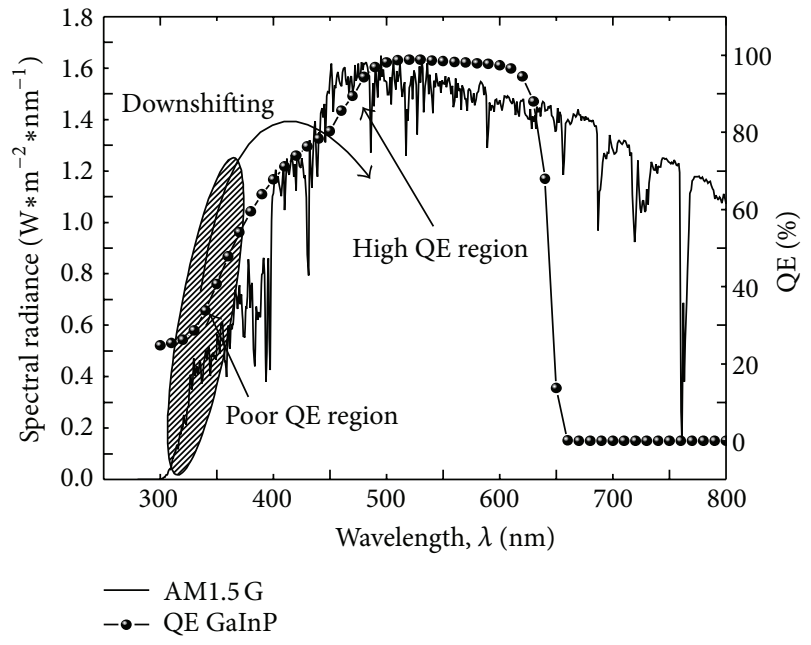

Figure 1: Solar spectrum AM1.5G, quantum efficiency of GaInP cell, and principle of downshifting.

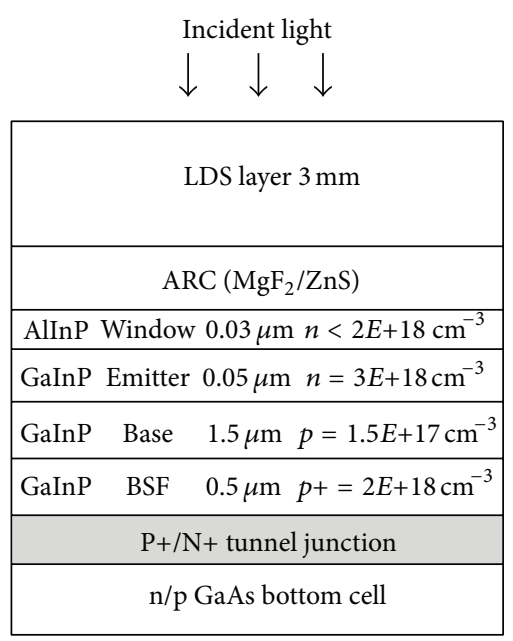

FIGURE 2: Schematic of a multijunction solar cell with LDS layer.

$900 \mathrm{~nm}$ to less than $2 \%$ [21]. The main parameters used in the calculations are shown in Table 2.

Simulations of the heterostructure were performed using the solar cells simulator SCAPS1-D (solar cell capacitance simulator in one dimension), developed at ELIS laboratory (Electronics and Information Systems) in GENT University, Belgium [22].

2.4. Simulation Methods. To study the gain in the efficiency of GaInP solar cells as a function of the organic dyes, we made 
TABLE 2: Main material parameters used in the simulation.

\begin{tabular}{lcc}
\hline Material & GaInP & AlInP \\
\hline Band Gap $(\mathrm{eV})$ & $1.9[15]$ & $2.4[1]$ \\
Electron affinity $(\mathrm{eV})$ & $4.1[15]$ & $4.2[1]$ \\
CB effective density of states & $1.3 E+20$ & $1.08 E+20$ \\
$\left(\mathrm{~cm}^{-3}\right)$ & {$[15]$} & {$[16]$} \\
$\left.\mathrm{VB} \mathrm{effective} \mathrm{density} \mathrm{of} \mathrm{states}^{-3}\right)$ & $1.28 E+19$ & $1.28 E+19$ \\
$\left(\mathrm{~cm}^{-3}\right)$ & {$[15]$} & {$[16]$} \\
Electron thermal velocity $(\mathrm{cm} / \mathrm{s})$ & $1.00 E+6$ & $1.00 E+7$ \\
& {$[15]$} & {$[16]$} \\
Hole thermal velocity $(\mathrm{cm} / \mathrm{s})$ & $1.00 E+6$ & $1.00 E+7$ \\
& {$[15]$} & {$[16]$} \\
Electron mobility $\left(\mathrm{cm}^{2} / \mathrm{Vs}\right)$ & Varied & $100[16]$ \\
Hole mobility $\left(\mathrm{cm}^{2} / \mathrm{Vs}\right)$ & {$[17,18]$} & $10[16]$ \\
Lattice constant $a\left(\mathrm{~A}^{\circ}\right)$ & $40[17,18]$ & $16.65[15]$ \\
Absorption coefficients $\alpha\left(\mathrm{m}^{-1}\right)$ & Data from & Data from \\
& {$[19]$} & {$[20]$} \\
\hline
\end{tabular}

a luminescent cascade (absorption and reemission) of photons so that a wide absorption can be reached. Several dyes can be mixed together within one layer in order to improve their absorption bandwidth, the Violet 570 absorption peak lies in the low QE region; however, it emits photons at wavelengths of Yellow 083 absorption range. This last emits photons at wavelengths of Orange 240 absorption range which in turn emits photon in the high QE region of the cell that ensures a better exploitation of the incident spectrum by the cell. Table 3 presents the three mixtures used in our study; the thickness of the PMMA used for the three samples is $3 \mathrm{~mm}$; dyes' concentration was chosen to yield a peak absorption around $70 \%-90 \%$ in a $3 \mathrm{~mm}$ thick sample, typically the PMMA concentration is around 2-3 ppm (parts per million) [23].

The LDS layer is assumed to have complete absorption of all light incidents with wavelengths shorter than $400 \mathrm{~nm}$. These dyes (Violet 570, Yellow 083, and Orange 240) were chosen because of their relatively high absorption coefficients and photoluminescent quantum yield (PLQY) [23].

When the structure (GaInP with LDS layer) is exposed to the incident solar spectrum $\varphi_{s}(\lambda)$, it is affected and modified by absorption and emission of photons in the PMMA mixed layer. The resulting spectrum $\varphi_{\text {sae }}(\lambda)$ is calculated from the amount of the absorbed and emitted photons. Furthermore, three quarters of the emitted photons are directed towards the solar cell, due to the internal reflection within the converter layer; the dye emission is isotropic [24].

The amount of photons absorbed depends on the thickness and the concentration of dyes in the LDS layer and is determined from the absorption spectrum of the dyes. The photon flux density decays exponentially after crossing a distance $x$ in PMMA layer $\varphi(x, \lambda)=\varphi_{0}(\lambda) \exp (-\alpha(\lambda) \times x)$ where $\alpha(\lambda)$ is the absorption coefficient $\left(\mathrm{cm}^{-1}\right)$ of the LDS layer, and the exponential term is given by $\alpha(\lambda) \times x=\varepsilon_{\lambda} \times C \times$ $D$, where $\varepsilon_{\lambda}$ is the molar extinction coefficient $\left(\mathrm{M}^{-1} \mathrm{~cm}^{-1}\right)$, $C$ is the concentration (M), and $D$ is the thickness of film
TABLE 3: The three mixed samples of PMMA doped with organic dyes used in the present study.

\begin{tabular}{lc}
\hline Sample & Characteristic \\
\hline S1 & PMMA doped with Violet 570 dye \\
S2 & S1 + Yellow 083 dye \\
S3 & S2 + Orange 240 dye \\
\hline
\end{tabular}

(cm). In addition, the absorption is enhanced if the thickness of the PMMA and the concentration of the dyes are higher, besides, the amount of photons emitted in the infrared region $\varphi_{e}(\lambda)$ is calculated from the dyes emission spectrum, and the resulting spectrum $\varphi_{\text {sae }}(\lambda)$ serves as an input for the solar cell simulation models $[24,25]$ :

$$
\varphi_{\text {sae }}(\lambda)=\varphi_{s}(\lambda)-\varphi_{a}(\lambda)+\varphi_{e}(\lambda)
$$

where $\varphi_{s}(\lambda)$ is the incident solar spectrum, $\varphi_{a}(\lambda)$ the amount of photons absorbed by dyes introduced in PMMA layer, and $\varphi_{e}(\lambda)$ the amount of photons emitted by dyes introduced in PMMA layer.

The short-circuit current density $\left(J_{\text {sc }}\right)$ of a solar cell is a function of the cell's quantum efficiency QE $(\lambda)$ and the resulting spectrum $\varphi_{\text {sae }}(\lambda)$ :

$$
J_{\mathrm{sc}}=q \int_{\lambda_{1}}^{\lambda_{2}} \mathrm{QE}(\lambda) \times \varphi_{\text {sae }}(\lambda) d(\lambda)
$$

where $q$ is the elementary charge and $\lambda_{1}$ and $\lambda_{2}$ define the range of the spectrum for which the $J_{\mathrm{sc}}$ is to be calculated.

It follows that, in order to increase the short-circuit current density in the cell, more photons must be shifted from the poor $\mathrm{QE}$ region to the higher $\mathrm{QE}$ region.

\section{Simulation Results and Discussions}

The performance of the GaInP solar cell was simulated without an LDS layer, and the obtained results were in accordance with those in the literature [21]. When an LDS layer is introduced on the top of the solar cell, organic dyes produce a substantial modification on the incident AM1.5G spectrum; they oblige the photons in the ultraviolet region to shift towards the visible region. The simulation is carried out for different numbers of organic dyes (S1, S2, and S3); for each case the effect on AM1.5G spectrum is shown in Figure 3.

SCAPS-1D simulations were carried out using the three samples of mixed dyes (S1, S2, and S3), using the resulting modified spectrum as an input for our simulation model. The variation of fill factor and open-circuit voltage with respect to the number of dyes added is presented in Figure 4 where it is clear that the open circuit voltage $\left(V_{\mathrm{oc}}\right)$ and fill factor $(\mathrm{FF})$ do not change significantly. This is due to the fact that there is no change in the electronic properties of the semiconductor material or in the resistance of the device.

On the other hand, we see from Figure 5 that the variations in the short circuit current density and conversion efficiency are substantial. The increase in conversion efficiency is a result of the increasing current generation because 

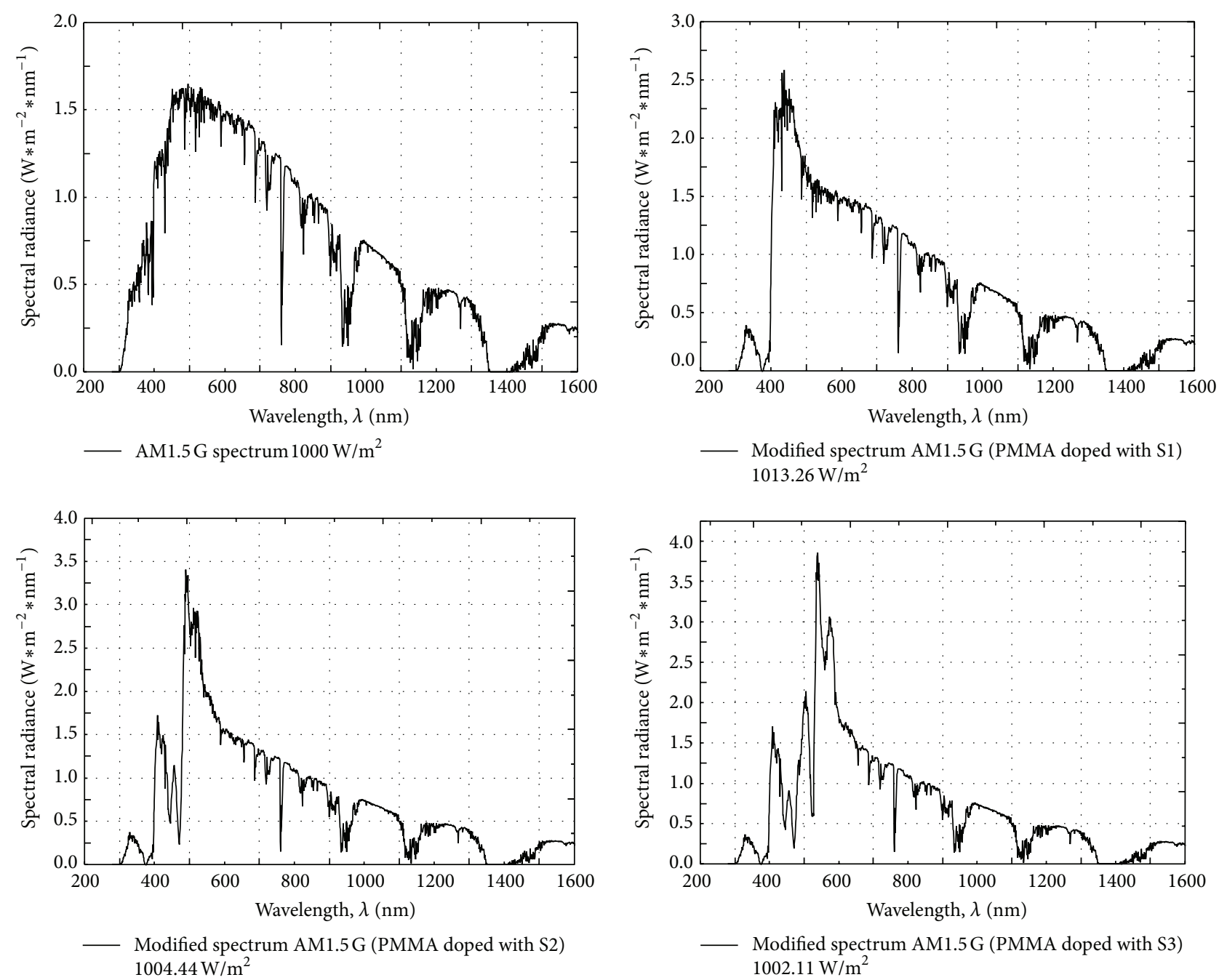

FIGURE 3: The luminescent downshift (LDS) effect on the AM1.5G solar spectrum.
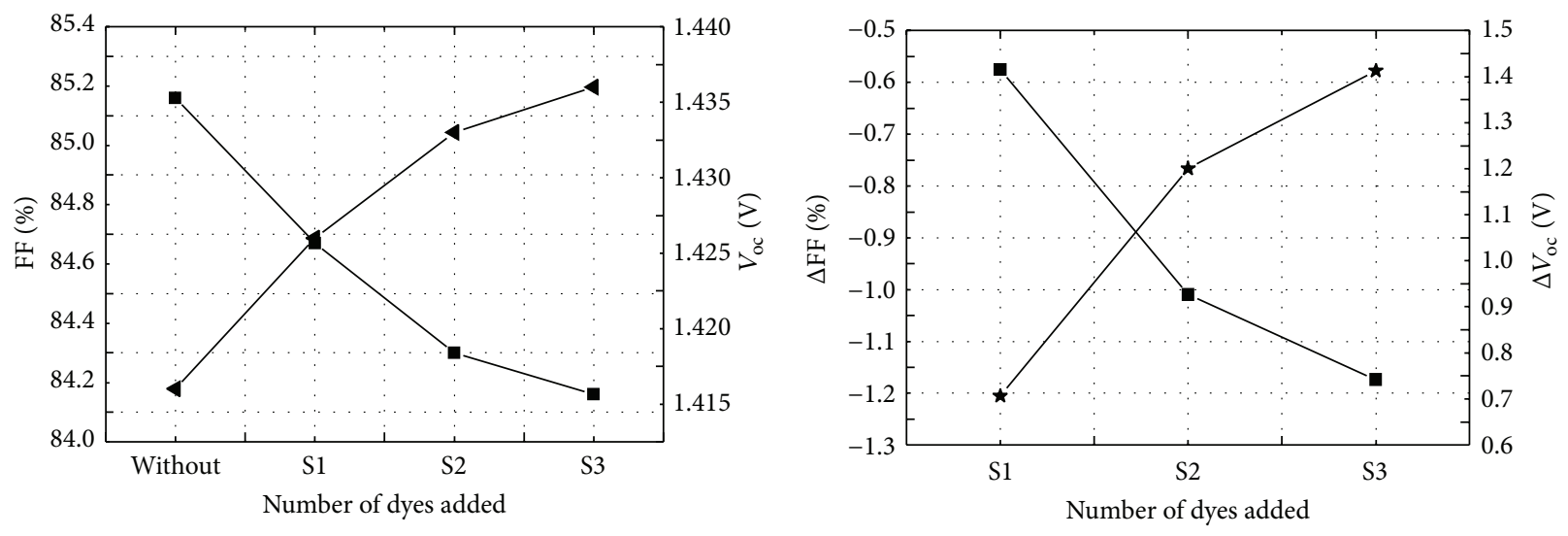

$$
\begin{array}{ll}
--\mathrm{FF} & -\Delta \mathrm{FF} \\
-4-V_{\mathrm{oc}} & -\star-\Delta V_{\mathrm{oc}}
\end{array}
$$

(a)

(b)

FIGURE 4: Simulation results of the variation of (a) fill factor and open-circuit voltage with the number of dyes added and (b) increase in fill factor and open-circuit voltage with the number of dyes added. 


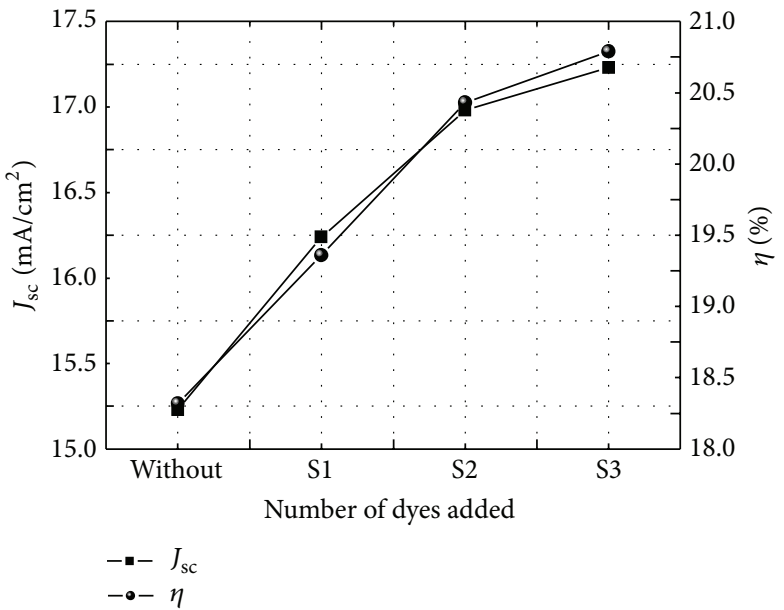

(a)

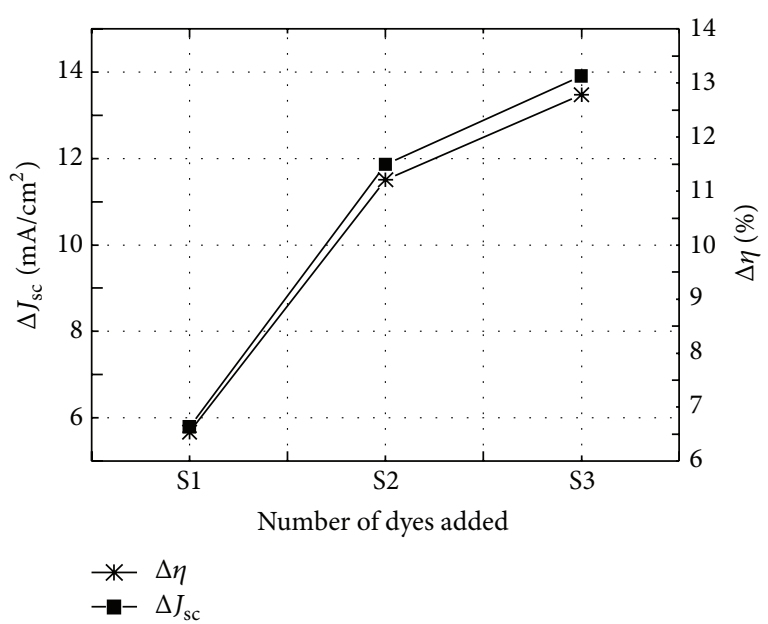

(b)

FIGURE 5: Simulation results of (a) the short-circuit current density and conversion efficiency variation with the number of dyes added and (b) the increase in the short-circuit current density and conversion efficiency variation with the number of dyes added.

TABLE 4: Short-circuit current density and efficiency of the GaInP solar cell with and without LDS.

\begin{tabular}{|c|c|c|c|c|c|}
\hline $\begin{array}{l}J_{\text {sc }}\left(\mathrm{mA} / \mathrm{cm}^{2}\right) \\
\text { GaInP cell } \\
\text { without PMMA }\end{array}$ & $\begin{array}{c}J_{\mathrm{sc}}\left(\mathrm{mA} / \mathrm{cm}^{2}\right) \\
\text { GaInP cell with } \\
\text { PMMA doped } \\
(\mathrm{S} 3) \\
\end{array}$ & $\begin{array}{c}\eta(\%) \\
\text { GaInP cell without } \\
\text { PMMA }\end{array}$ & $\begin{array}{c}\eta(\%) \\
\text { GaInP cell with } \\
\text { PMMA doped } \\
(\mathrm{S} 3) \\
\end{array}$ & $\begin{array}{c}J_{\text {sc }} \text { current improve } \\
(\%)\end{array}$ & $\begin{array}{c}\text { Efficiency } \eta \text { improve } \\
(\%)\end{array}$ \\
\hline 15.23 & 17.23 & 18.32 & 20.79 & 13.13 & 13.48 \\
\hline
\end{tabular}

the short-circuit current density varies proportionally with the quantity of photons shifted by the LDS layer.

The study of the improvements brought by the LDS layer on the GaInP solar cell, as a function of the number of dyes added, has shown that better results are achieved for the samples S1 and S2 (violet, violet, and yellow) with gains in short-circuit current density of $6.63 \%$ and $4.86 \%$, respectively, whereas the addition of the third dye contributes only with $1.64 \%$ in the total increase. This is due to the fact that the $\mathrm{QE}$ of GaInP is poor in the absorption and emission spectrum of the two samples S1 and S2; hence, there is more photon transfer from UV and blue regions, where the collection probability of these photons is lower to the visible region, where the probability of collection is higher. Furthermore, when we add the third dye (orange 240) to S2, it induces absorption and reemission of photons in the region where the $\mathrm{QE}$ of the cell is already high (QE above 80\%). So, there is less contribution in the collected current of the GaInP solar cell.

The simulated J-V characteristics of the GaInP structure with and without our specific downshift (PMMA doped with S3) are shown in Figure 6 where we observe an important increase in the short circuit current density and the cell's conversion efficiency. The gains in short-circuit current density and the conversion efficiency are summarized in Table 4.

\section{Conclusion}

We proved, in this work, that the performances of the GaInP top monolithic solar cell are improved by introducing

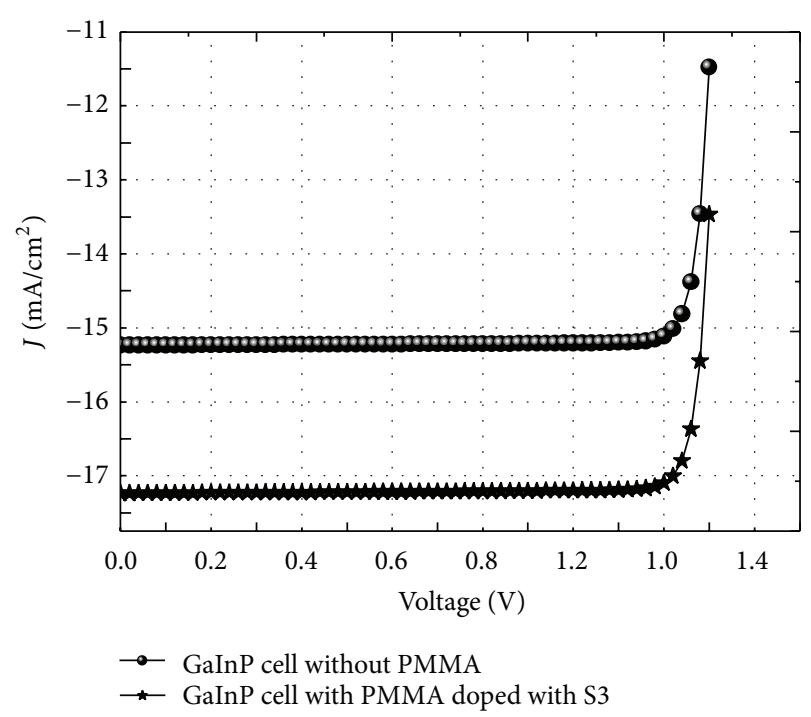

FIGURE 6: Simulation results of GaInP solar cell characteristics with and without LDS PMMA layer.

luminescence downshifting (LDS) layers. These performances have been simulated as a function of the mixture of the organic dyes (Violet 570, Yellow 083, and Orange 240). The simulation results have shown that, under the AM1.5G illumination spectrum, increases in the short-circuit current density and in the conversion efficiency of $13.13 \%$ and $13.48 \%$ 
are, respectively, achieved by using an LDS layer doped by a mixture of the three dyes (Violet 570, Yellow 083, and Orange 240).

The two organic dyes Violet 570 and Yellow 083 have a great contribution in augmenting the efficiency of the solar cell compared to the Orange 240 dye; hence, they are more suited for GaInP solar cells with an LDS layer.

The use of an LDS layer allowed an increase in the efficiency of the GaInP top cell to values above $20 \%$. Finally, in order to improve the solar cell performances, we plan in future works to study the behavior of the tandem solar cell with several dyes concentrations and obtain the optimum concentration corresponding to this structure.

\section{Acknowledgment}

The authors wish to thank Dr. M. Burgelman's group of Electronics and Information Systems (ELIS), University of Gent, for the SCAPS-1D program tool.

\section{References}

[1] A. Luque and S. Hegedus, Handbook of Photovoltaic Science and Engineering, John Wiley \& Sons, Hoboken, NJ, USA, 2003.

[2] P. J. Faine, R. Sarah Kurtz, and J. M. Olson, "Modeling of twojunction, series-connected tandem solar cells using top-cell and coating thicknesses as adjustable parameters," in Proceedings of the 21st IEEE Photovoltaics Specialists Conference (PVSC '90), Kissimmee, Fla, USA, 1990.

[3] J. M. Olson, S. R. Kurtz, A. E. Kibbler, and P. Faine, "A 27.3\% efficient $\mathrm{Ga}_{0.5} \mathrm{In}_{0.5} \mathrm{P} / \mathrm{GaAs}$ tandem solar cell," Applied Physics Letters, vol. 56, no. 7, pp. 623-625, 1990.

[4] S. R. Kurtz, P. Faine, and J. M. Olson, "Modeling of twojunction, series-connected tandem solar cells using top-cell thickness as an adjustable parameter," Journal of Applied Physics, vol. 68, no. 4, pp. 1890-1895, 1990.

[5] D. Ross, E. Klampaftis, J. Fritsche, M. Bauer, and B. S. Richards, "Increased short-circuit current density of production line CdTe mini-module through luminescent down-shifting," Solar Energy Materials and Solar Cells, vol. 103, pp. 11-16, 2012.

[6] E. Klampaftis, D. Ross, K. R. McIntosh, and B. S. Richards, "Enhancing the performance of solar cells via luminescent down-shifting of the incident spectrum: a review," Solar Energy Materials and Solar Cells, vol. 93, no. 8, pp. 1182-1194, 2009.

[7] L. Danos, T. Parel, T. Markvart, V. Barrioz, W. S. M. Brooks, and S. J. C. Irvine, "Increased efficiencies on CdTe solar cells via luminescence down-shifting with excitation energy transfer between dyes," Solar Energy Materials and Solar Cells, vol. 98, pp. 486-490, 2012.

[8] H. J. Hovel, R. T. Hodgson, and J. M. Woodall, "The effect of fluorescent wavelength shifting on solar cell spectral response," Solar Energy Materials, vol. 2, no. 1, pp. 19-29, 1979.

[9] ASTM-Standard-G173-2003el, "Standard TABLEs for Reference solar spectral irradiances: Direct normal and hemispherical on 37 degree tilted surface," Conshohocken, Pa, USA, 2003.

[10] A. Vesselinka Petrova-Koch and R. Hezel Adolf Goetzberger, High-Efficient Low-Cost Photovoltaics Recent Developments, Springer, Berlin, Germany, 2009.

[11] B. S. Richard and A. Shalav, "The role of polymers in the luminescence conversion of sunlight for enhanced solar cell performance," Synthetic Metals, vol. 154, no. 1-3, pp. 61-64, 2005.
[12] K. R. McIntosh, G. Lau, J. N. Cotsell et al., "Increase in external quantum efficiency of encapsulated silicon solar cells from a luminescent down-shifting layer," Progress in Photovoltaics, vol. 17, no. 3, pp. 191-197, 2009.

[13] "BASF Lumogen F datasheets," http://www2.basf.us/additives /pdfs/lumvio570.pdf, http://www2.basf.us/additives/pdfs/lumyel083.pdf.

[14] B. S. Richards and K. R. McIntosh, "Increased mc-Si module efficiency using fluorescent organic dyes: a ray-tracing study," in IEEE 4th World Conference on Photovoltaic Energy Conversion, Waikoloa, Hawaii, USA, May 2006.

[15] K. J. Singh and S. K. Sarkar, "Highly efficient ARC less InGaP/ GaAs DJ solar cell numerical modeling using optimized InAlGaP BSF layers," Optical and Quantum Electronics, vol. 43, pp. $1-21,2011$.

[16] A. S. Gudovskikh, N. A. Kaluzhniy, V. M. Lantratov, S. A. Mintairov, M. Z. Shvarts, and V. M. Andreev, "Numerical modelling of GaInP solar cells with AlInP and AlGaAs windows," Thin Solid Films, vol. 516, no. 20, pp. 6739-6743, 2008.

[17] K. Ikeda and M. Kaneko, "Estimation of the composition parameter of electrochemically colored amorphous hydrogen tungsten oxide films ," Journal of Applied Physics, vol. 66, Article ID 5285, 6 pages, 1989.

[18] M. Y. Ghannam, A. S. Alomar, N. Posthuma, G. Flammad, and J. Poorthmans, "Optimization of the triple junction $\operatorname{In}_{0.5} \mathrm{Ga}_{0.5} \mathrm{P} /$ GaAs/Ge monolithic tandem cell aimed for terrestrial applications using an experimentally verified analytical model," Kuwait Journal of Science and Engineering, vol. 31, pp. 203-234, 2004.

[19] L. Guijiang, W. Jyhchiarng, and H. Meichun, “Theoretical modeling of the interface recombination effect on the performance of III-V tandem solar cells," Journal of Semiconductors, vol. 31, no. 8, Article ID 082004, 2010.

[20] S. Adachi, Optical Constants of Crystalline and Amorphous Semiconductors-Numerical Data And Graphical Information, Springer, New York, NY, USA, 1999.

[21] T. Takamoto, E. Ikeda, H. Kurita, and M. Ohmori, "High efficiency InGaP solar cells for InGaP/GaAs tandem cell application," in Proceedings of the 1st World Conference on Photovoltaic Energy Conversion, pp. 1729-1732, Waikoloa, Hawaii, USA, December 1994.

[22] A. Niemegeers and M. Burgelman, "Effects of the Au/CdTe back contact on IV and CV characteristics of $\mathrm{Au} / \mathrm{CdTe} / \mathrm{CdS} / \mathrm{TCO}$ solar cells," Journal of Applied Physics, vol. 81, Article ID 2881, 1997.

[23] L. R. Wilson and B. S. Richards, "Measurement method for photoluminescent quantum yields of fluorescent organic dyes in polymethyl methacrylate for luminescent solar concentrators," Applied Optics, vol. 48, no. 2, pp. 212-220, 2009.

[24] W. G. J. H. M. van Sark, "Simulating performance of solar cells with spectral downshifting layers," Thin Solid Films, vol. 516, no. 20, pp. 6808-6812, 2008.

[25] W. G. J. H. M. Van Sark, A. Meijerink, R. E. I. Schropp, J. A. M. Van Roosmalen, and E. H. Lysen, "Enhancing solar cell efficiency by using spectral converters," Solar Energy Materials and Solar Cells, vol. 87, no. 1-4, pp. 395-409, 2005. 

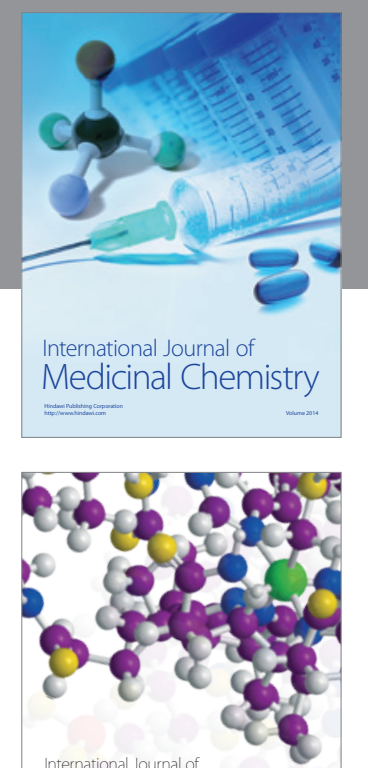

\section{Carbohydrate} Chemistry

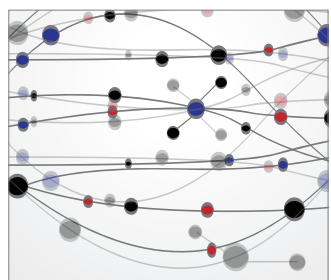

The Scientific World Journal
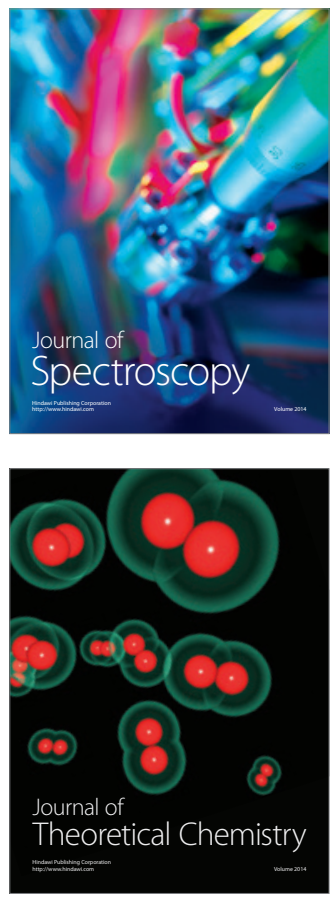
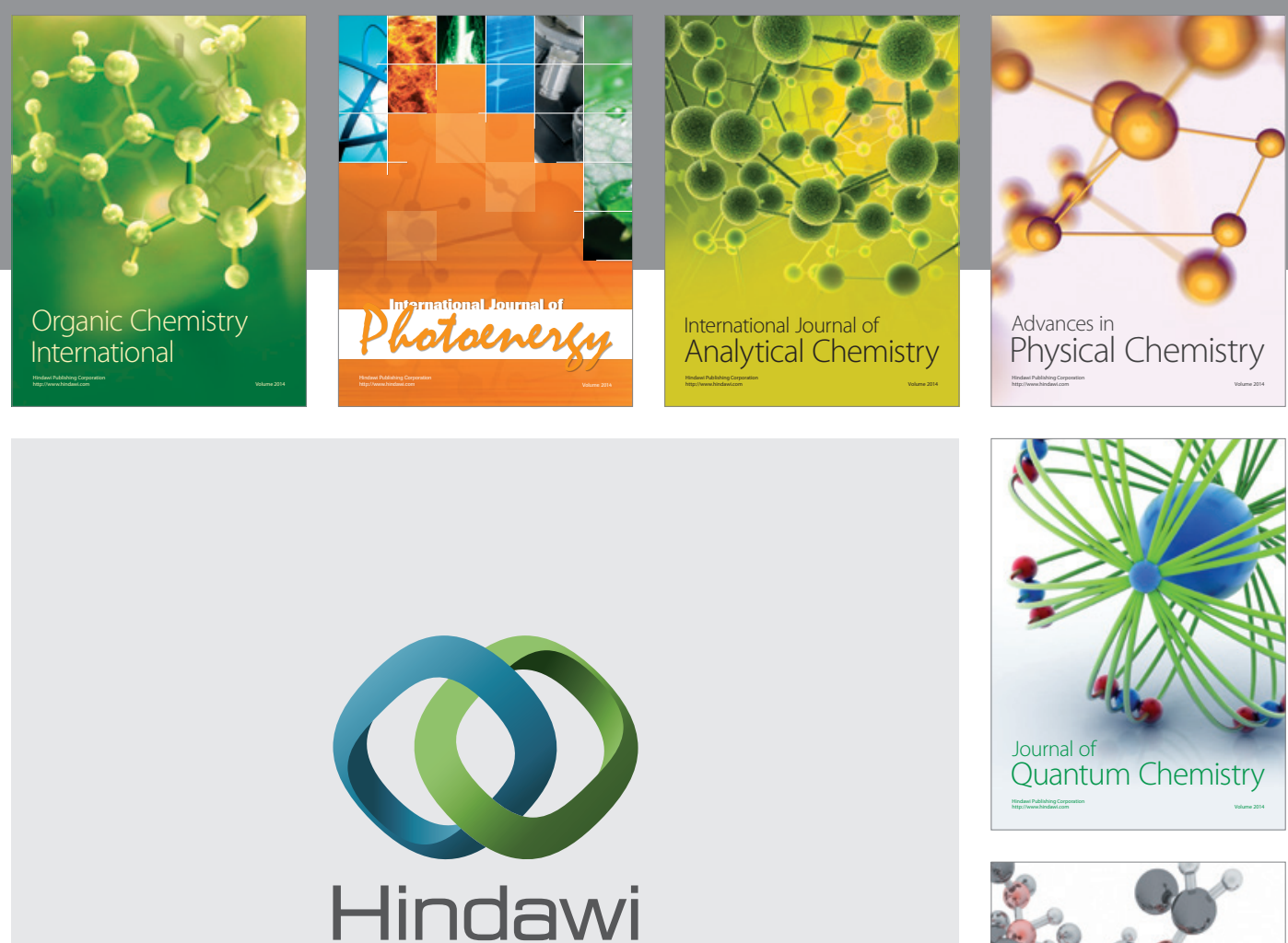

Submit your manuscripts at

http://www.hindawi.com

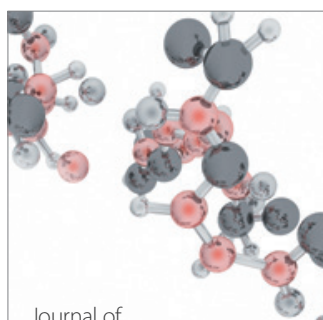

Analytical Methods

in Chemistry

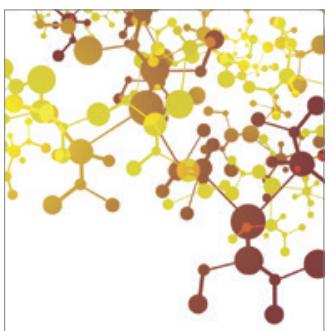

Journal of

Applied Chemistry

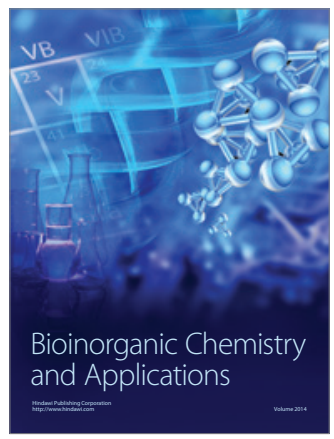

Inorganic Chemistry
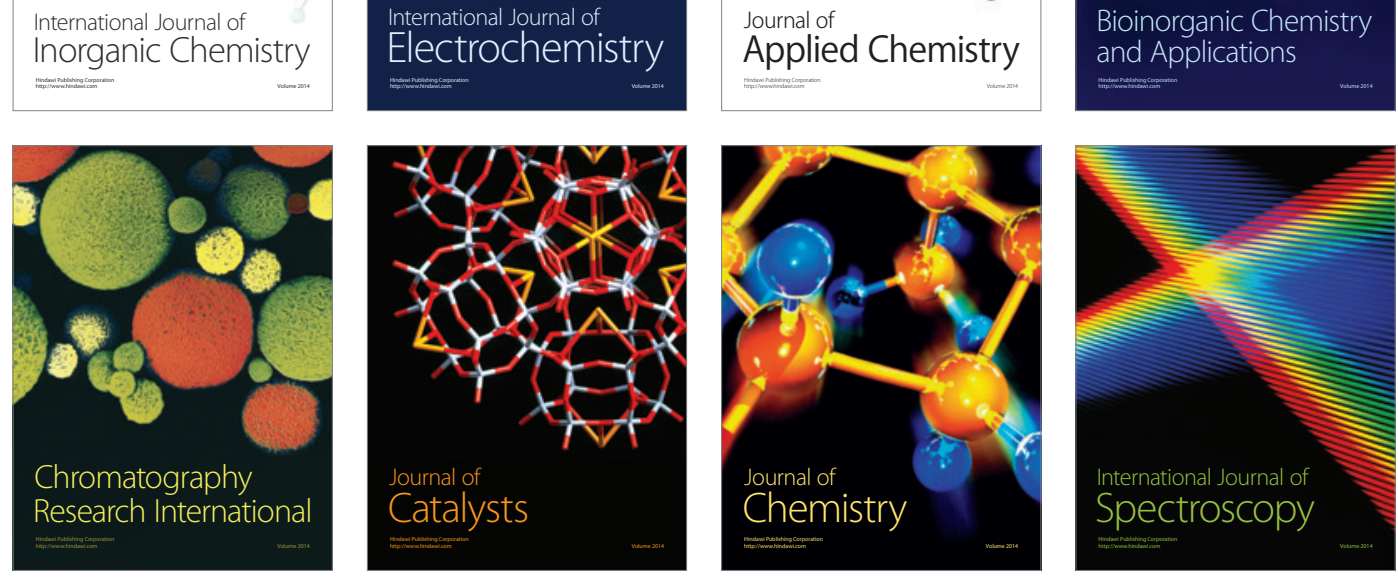